\title{
Sample Activities in Teaching Functions through ICT Support
}

\author{
Selin Urhan ${ }^{1, *}$, Gizem $\mathrm{Kuh}^{2}$, Irem Günal ${ }^{3}$ and Selay Arkün Kocadere ${ }^{4}$ \\ ${ }^{1}$ Hacettepe University, Department of Mathematics and Science Education, Ankara, Türkiye \\ ${ }^{2}$ Reyhanlı Şahika College, Hatay, Türkiye \\ ${ }^{3}$ Aydin Bahçeşehir College Anatolian High School, Aydın, Türkiye \\ ${ }^{4}$ Hacettepe University, Department of Computer Education and Instructional Technology, Ankara, \\ Türkiye
}

\begin{abstract}
Functions are one of the most important topics of algebra in which the success rate of students is quite low and many misconceptions are commonly encountered. Studies argue that by means of technological support, mathematics teaching in general and functions in particular will be facilitated. On the other hand, the rapid development in technology and digital natives necessitate the integration of technology into the field of education. The aim of this study is to present sample activities with regard to the integration of information and communication technologies into the teaching and learning process of functions by using readily available econtents; Autograph, one of the softwares used for mathematics teaching; and other basic tools.
\end{abstract}

Keywords: Teaching mathematics, instructional technologies, function, ICT, ICT integration.

\section{Introduction}

Function is one of the most important topics of mathematics as it involves basic concepts of algebra and helps understand and associate other mathematical topics in algebra [1, 2]. However, as it has a complex and abstract nature, students have difficulty understanding the functions and cannot learn the function concept in mathematics at the desired level [1, 3, 4, $5]$.

One of the main reasons why students have difficulty in functions is that they make some wrong generalizations about the topic, especially about the definition of function [6, 7, 8]. Many students see functions only as a matching, a formula, an equation, or a rule [4]. Some students believe that what makes a function is the concept of variable, and that when there is no variable, a given expression, i.e. the constant function, does not signify a function [9]. Furthermore, there are students who think that every function expression they encounter must be injective and surjective $[6,8,9]$. Some students consider the relations that match one element in the domain with more than one element in the range as a function [10]. On the other hand, it was also found that while writing ordered pairs, students believe

* Corresponding author: $\underline{\text { selin.urhan } @ \text { hacettepe.edu.tr }}$ 
that the first component represents the range and the second component represents the domain [10].

Ozmantar, Bingölbali, and Akkoç [10] report that although the x-axis shows the domain, and the y-axis shows the range, students are generally confused about this. Güveli [11] found that most students are unable to reflect the algebraic expression of the function on the graph of function, or they have difficulty in doing so. Carlson and Oehrtman [12] revealed that students have difficulty in algebraic and graphical representation of particularly the partially defined functions. It has been found most students believe that function can be defined by a single algebraic formula, and thus, their graphs cannot have a disconnection.

Polat and Şahiner [8] state that students do not associate function with everyday life situations and they consider it as a product of a disconnected and a totally abstract world. Thus, students fail when they are asked to give examples of functions from everyday life or to explain a situation with algebraic or graphical representations of functions.

According to Carlson and Oehrtman [12], students also have difficulty with inverse functions. It has been observed that students do not know why they follow some certain steps to find the inverse of an algebraic function algebraically or based on graph, and also they forget these steps in a short time as they apply them without making sense of them.

In order to reduce the difficulties faced by students in learning functions, researchers have made various suggestions. In this context, Ural [13] emphasized the importance of the teaching method and teaching materials. Dikici and Isşleyen [14] and Carlson and Oehrtman [12] stated that functions should be taught by visualizing them with graphs and diagrams. Akkoç [15] stated that examples for descriptive characteristics should be increased.

According to Kabael [4], especially the first parts of the function topic should be taught to the students through visualization and concretization as much as possible. In this context, it would be quite effective to associate function with a machine that produces output values depending on a specific rule for some input values, and even to use a machine model made from a cardboard to teach the subject. Polat and Şahiner [8] stated that the use of technological tools will be effective in the teaching of the function. Kabael [4] argues that the use of appropriate computer programs in the following sections of the topic will be useful for effective teaching of function graphs. According to Kabael [4], as computer programs draw function graphs quickly and effectively, students have time to think and comment on the graphs and thus they can relate the algebraic and graphical representations of functions. Tüzün, Arkün, Bayırtepe, Kurt and Yermeydan Uğur [16] found that the educational computer game they developed can be used as an effective tool to teach the function concept and its types. Kutluca and Baki [17] reported that the computer-assisted worksheets they developed with the help of electronic spreadsheets and computer algebra systems to teach second-order functions have saved teaching from monotony and enabled students to become more motivated by attracting their attention. Brown [18] found that students in the technology-supported learning environments constructed by computers and TI 83/83 + calculators for effective teaching of functions performed better than students who worked on functions only manually. Lagrange [19] revealed that the exploration and modeling of a concept with the aid of a technological tool helps students understand the related concept better. In their study, Mwangi, Waweru and Mwathi [20] designed a computer game to teach functions and they reported that the students found the process very fast and they understood the difference between relations and function better.

Studies frequently point to the contribution and necessity of technology integration in the learning and teaching process of mathematics in general and functions in particular. On the other hand, the habits of new generation defined as digital natives and the human power needed in the age of knowledge necessitate the use of technology in education as well as in many other areas. 


\section{Aim of the study}

The aim of this study is to present a series of sample activities aimed at integrating information and communication technologies with the teaching-learning process using the infrastructure that FATIH project, which is the most extensive work aiming at the integration of technology into the teaching process in Turkey offers; ready-to-use e-content like EBA and Vitamin; Autograph, which is one of the special software for mathematics teaching, and simple tools that do not require high technical skills and knowledge. For this purpose, activities aiming at achieving the outcomes of the functions topic with technology support have been selected or developed. In this way, it is aimed to create an awareness of the effective use of the opportunities offered and to set an effective example to prepare instructional environments for the integration of technology into the teaching process with the aid of simple tools.

\section{Activities for teaching functions}

A story was written by the researchers reflecting the daily life situation of the learning outcome of "Students explain the concept of function" and it was visualized using the Prezi presentation tool. In this story, the student, Arda, is elected the class president. The teacher wants Arda to place his classmates in one of the activities in the school. It is imperative that each student in the class participate in an activity. However, it is not possible to participate in more than one activity since all activity club meetings are held on the same day at the same time. Through this story, it is aimed that students will define function as "the relation that matches each element of one set (domain) to one and only one element of another set (range)". It is also aimed to reduce the misconceptions of students such as not accepting the relations that match more than one element in the domain with the same element in the range as a function, and accepting the relations that match one element in the domain with more than one element in the range as a function. Besides, it is aimed to prevent problems such as not being able to relate function to everyday life situations and considering function as a product of a disconnected, completely abstract world.

In the following parts of the lesson, the idea that "The function is a machine that produces $y$ output values for $x$ input values" is shown to students through an application in EBA at http://f.eba.gov.tr/MatematikAraclariUygulamasi/ as seen in Figure 1.

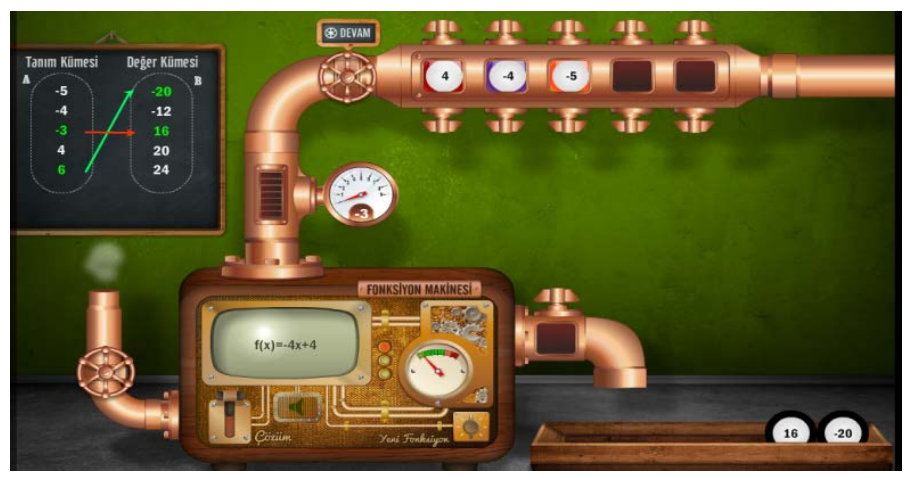

Fig. 1. Function machine application (EBA)

In the application "Function Machine", there is a machine programmed to produce output values $(f(x))$ for some input values $(x)$ based on a certain rule. In this application, students are asked to assign the input value for a given function to the machine and to 
calculate the output value corresponding to the input value. When students push the "Control" key, the machine gives feedback to students' answers as correct or incorrect. In the top left corner, the domain and range of the function and the matching of the input values with the appropriate output values are given. In this way, it is aimed to enable students to learn the function concept with its multiple representations, and to prevent students from considering functions only as a match, a formula, an equation or a rule, and from thinking that every function expression must be injective and surjective. Besides, it is aimed to reduce the difficulties such as not being able to make enough sense of domain and range and confusing them, and not being able to convert a function given with one representation into another representation.

The Autograph software was used to achieve the learning outcome of "Students make the graphical representation of functions". With Autograph, students can see the graph drawn from different perspectives, and reach the coordinates of the points on the graph or the slope of the graph. Students are asked to enter the function expression into the window that opens from the "Equation" button in the Autograph coordinate plane and to determine the domain and range of the function looking at the graph. In this way, it will be possible to obtain the images of some elements in the domain as well as reverse images of some elements in the range. Thus, the outcomes of "The domain and range are shown on the graph of the function" and "The image of some elements in the domain of a given function and the reverse images of some elements in the range are determined" will be reached in an effective way. With such activities structured through Autograph, it is aimed to reduce difficulties like not being able to transform the function given with algebraic expression into graphical representation, seeing the graph of function as a constant object, not being able to determine the domain and range of the function based on the graph, confusing that the $x$-axis represents the domain and the $y$-axis represents the range.

The outcome "In the graph of a function, the line drawn parallel to the $y$-axis from a point where the function is defined on the $x$-axis cuts the graph at only one point (vertical/perpendicular line test)" is planned to be achieved with an Autograph activity as seen in Figure 2. In this activity, algebraic expressions will be presented to the students. Students will be asked to draw graphs of algebraic expressions using Autograph and to draw vertical lines passing through the $x$ coordinate of any point on the graph. The result to be reached is that when any of the drawn lines cut the graph at more than one point, the graph will not represent a function, and when the drawn lines cut the graph at only one point, the graph will show a function. With this activity, it is aimed to eliminate the misconception of accepting the relations matching one element in the domain with more than one element in the range as function.

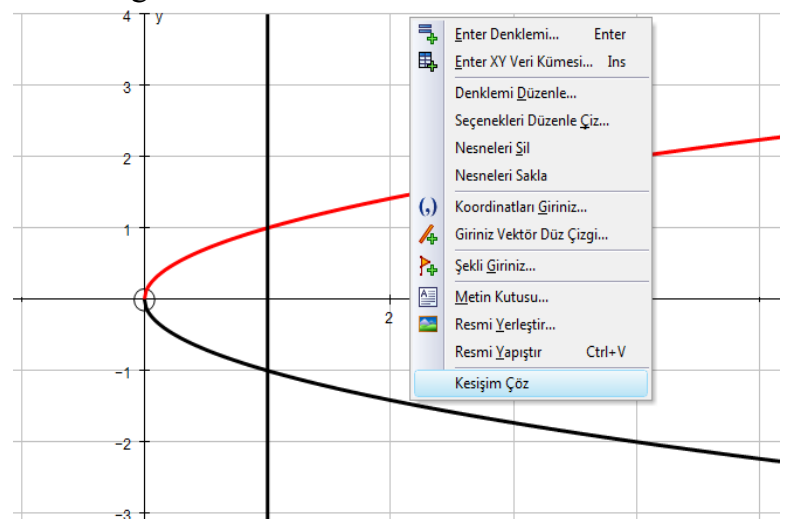

Fig. 2. Vertical line test in Autograph 
To achieve the objective of "The graphs of partially defined functions are drawn and the related operations are performed. In this context, the absolute value function is also given as an example of a partially defined function", the EBA activity (http://f.eba.gov.tr/MatematikAraclariUygulamasi/) was used as seen in Figure 3. In this application, how the graph will change by changing the discontinuity point in partially defined functions is observed. Also, the function of absolute value is addressed. In the activity, students are asked to change the discontinuity value of $x$ and the coefficients of the functions. In this way, students are expected to examine the formation of partially defined functions according to the critical value of $x$ (discontinuity value). Through multiple representations (algebraic and graphical) of the partially defined functions, it is aimed to reduce the difficulties students experience in both algebraic and graphical representations.
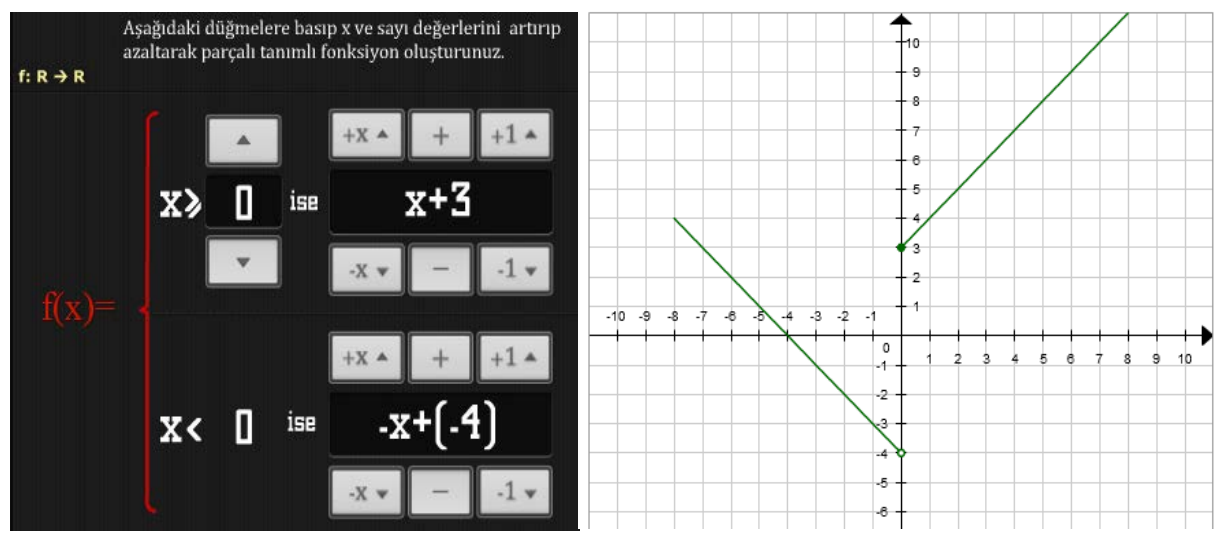

Fig. 3. An application for the graph of partially defined functions (EBA)

To reach the objectives of "Activities about the graphs of the functions in the form of $f(x)=a x+b$ are carried out" and "The relationship between the rate of change and the slope of the line is addressed", the activity under the "first-degree functions" category in the "function graphics" section in EBA (http://f.eba.gov.tr/MatematikAraclariUygulamasi/) was utilized. In this application, it is aimed to help students discover how the graph of the function changes as a result of the change in the $a$ value, which is the coefficient of $x$, in a linear function expression given as $f(x)=a x+b$. Students are asked to change the $a$ value in the function expression and interpret how the graph changes; they are also asked to identify the domain and range of the function at each change. Here, it is aimed to avoid the difficulties experienced by students like seeing the graph of the function as a fixed object, not being able to define the domain and range of function on the graph, and not being able to reflect the algebraic expression of the function on the graph of the function. In this process, it is also possible for students to see that the function is a constant function when $a$ value is 0 . It is also aimed to eliminate the misconceptions of students that when there is no variable, a given expression cannot specify a function and a function graph should cut both the $x$ and $y$ axes.

To achieve the objective of "It is emphasized that the points at which the $f$ function intersects the $x$-axis are the solution set of the $f(x)=0$ equation at real numbers", an application in the Vitamin Lisego was utilized (http://www.vitaminegitim.com/proxy/HSStudentPlayerv0.0.228/index.html\#lessonplayer). In the application, the aim is to find the zeros (roots) of the functions and to determine the points where the functions are equal to each other using the intersection points of the two function graphs. With this activity, students are expected to generate solutions by 
developing higher-order thinking skills instead of trying to find the roots of the functions through many algebraic operations.

Another Vitamin Lisego applicaton was chosen to achieve the objective of "The image of some elements in the domain of a function whose graph was given and the reverse images of some elements in the range are determined" http://www.vitaminegitim.com/proxy/HSStudentPlayer_v0.0.228/index.html\#lessonplayer. In this activity, students are expected to find the images of some elements in the domain of functions and the reverse images of some elements in the range using function graphs. With this activity, it is aimed to eliminate misconceptions like not being able to make sense of domain and range and having confusion about the fact that the $x$-axis represents domain, and the $y$-axis represents range. In this activity, students are also asked to express the elements in the domain with the elements they match in the range as ordered pairs. In this way, it is aimed to avoid conceptual misconceptions such as thinking that the first component represents the range, while the second component represents the domain while expressing the ordered pairs.

The aim of another Vitamin Lisego activity is to find the domain and range of a function on the coordinate plane using the graph of the function as seen in Figure 4. With this activity, it is aimed to achieve the objective of "The domain and the range are shown on the graph of the function". It is thought that in this way, the conceptual misconceptions such as not being able to make sense of domain and range and having confusion about the fact that the $x$-axis represents domain and the $y$-axis represents range may be eliminated.

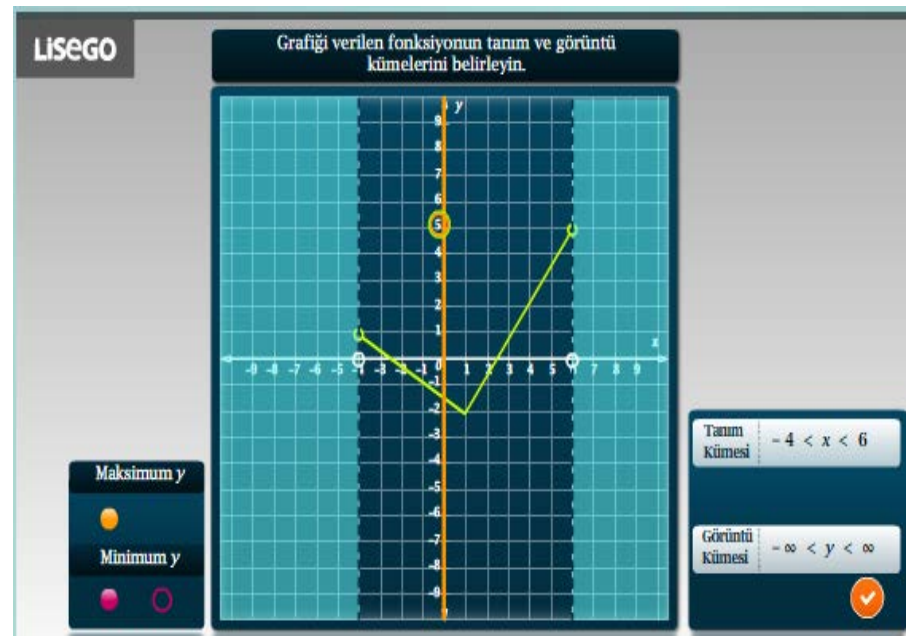

Fig. 4. Identifying the domain and range of the function using the graph of the function http://www.vitaminegitim.com/proxy/HSStudentPlayer_v0.0.228/index.html\#lessonplayer

An activity involving the use of Autograph was prepared to achieve the objective of "Students draw the graphs of functions in the form of $(x)=x^{n},(n \in Z)$ " as seen in Figure 5. In the first stage of this activity, students are asked to draw the graphs of functions in the form of $f: R \rightarrow R, f(x)=x^{n}$ for $n=3,5,7$ on the coordinate plane in the Autograph, and to interpret the change in the graphs as the $n$ value increases. In the second stage, students are expected to draw the graphs of functions of the same form for $n=2,4,6$ and to interpret the change in the graphs while the $n$ value increases. In the third stage, students are asked to compare the graphs and interpret the change in graphs for negative and even $n$ values and for the negative and odd $n$ values. With this activity, it is aimed to make it easier for students to understand the parabola and curve concepts, the differences between 
them, and which concept is formed when. It is also believed that some advanced mathematical skills of students can be improved by giving students the opportunity to interpret the results obtained by drawing a graph with software instead of by drawing a graph manually after complex and long algebraic operations.
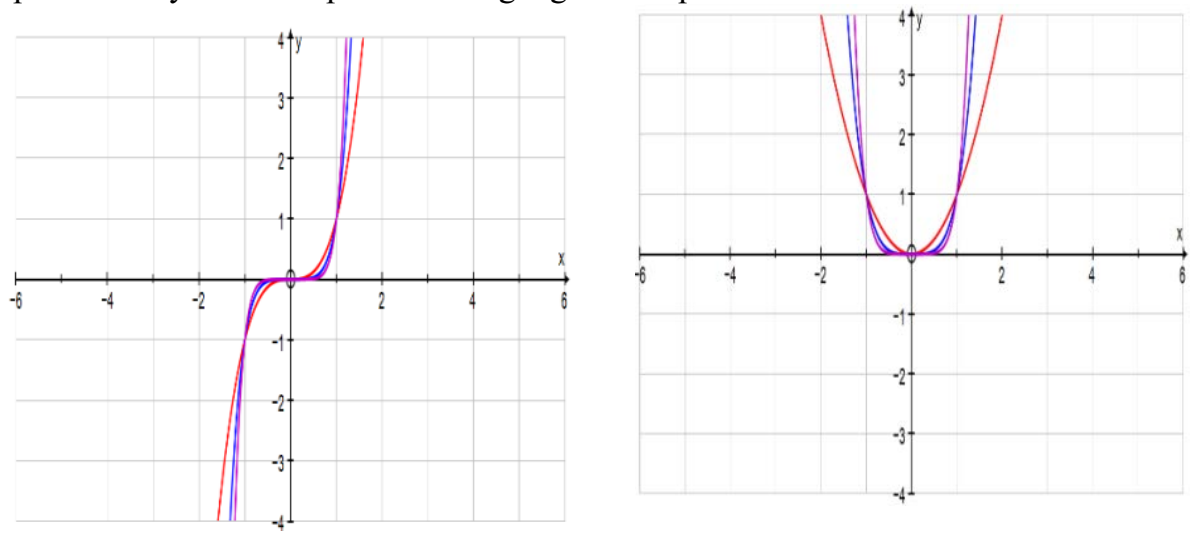

Fig. 5. Graphs for $f: R \rightarrow R, f(x)=x^{n}$ for $\mathrm{n}=2,4,6$ and $\mathrm{n}=3,5,7$

A drag-and-drop activity was developed by the researchers for the objective of "Students explain the injective and surjective functions". It is also aimed to present examples from daily life for functions. In the first part of the activity, students are asked to match the primary players in a school basketball team with the jerseys they will wear in the match using the scheme method, and then to determine which type of function this matching exemplifies. In the second part of the activity, it is stated that Arda, İlayda, Aslihan and Onur bought tickets for seats 19,20,21 and 22 for a theater play and students are asked to match these people with the seats using the scheme method and to find out what type of function this matching represents. In the last part of the activity, it is stated in an experiment in the biology class that Belgin's blood group is $A$, while Ergin's, Ceren's, Ilgin's, and Selen's blood groups are $0, B, B$, and $A B$, respectively. Students are asked to match these people with their blood groups using the scheme method. Students are also expected to determine which type of function their matching corresponds to. The activity aims to eliminate the misconception that every function has to be an injective and surjective function.

\section{Conclusions and suggestions}

It is stated in the literature that students have difficulty in making sense of functions, associating them with daily life, comprehending the definition of function, drawing function graphs, identifying the domain and range of function from its graph or algebraic expression, and understanding constant function, inverse function, composite function, and partially defined function. Studies aimed at minimizing these difficulties show that ICT integration may make important contributions to the teaching and learning process of functions. Studies by Brown [18], Kutluca and Baki [17], Lagrange [19], Mwangi and colleagues [20], and Tüzün and colleagues [16] are the examples of such studies. In these studies, teachers are particularly recommended to concretize the subject by giving examples from daily life and through visualizing, and to enrich the teaching process in the sections related to graphs and sub-concepts of the subject with computer programs, graphical calculators and other applications.

In this study, a series of activities related to the teaching of functions topic with the integration of ICT was presented. These activities are believed to raise awareness as to the 
effective use of tablets distributed within the scope of FATIH project and the e-content presented in EBA and Vitamin. Various teaching materials developed using simple tools that do not require high technical knowledge and skills and readily available software for mathematics were also included in the study.

The habits of the new generation defined as digital natives and the human power needed in the age of information necessitate the use of technology in education as in other fields. On the other hand, studies point to the contribution and necessity of technology integration in the teaching and learning process. Many investments are made in instructional technology all over the world, including Turkey. The improvement in education and raising individuals who meet the requirements of the present age depend on making good use of these investments. In this context, both educational researchers and teachers have a great responsibility. The increase in the number of studies like this, the production of high quality e-content, and effective in-service training sessions for teachers are the suggestions that could be put forward in this respect.

\section{References}

1. İ. Bayazıt, Matematiksel kavram yanılgıları ve çözüm önerileri, 91- 117. (2013).

2. National Council of Teachers of Mathematics, Principles and standards for school mathematics. (2000).

3. T. Dreyfus, Mathematics and cognition, ICMI study series, 113-134. (1990).

4. U.T. Kabael, Tübav Bilim Dergisi, 3, 1 128-136. (2010).

5. E. J. Knuth, Journal for Research in Mathematics Education, 31, 4 500-508. (2000).

6. E. Dubinsky, G. Harel, The concept of function: aspects of epistemology and pedagogy, 85-106. (1992).

7. R. Even, Educational Studies in Mathematic, 21, 6 521-554. (1990).

8. Z. S. Polat, Y. Şahiner, Eğitim ve Bilim, 32 89-94. (2007).

9. D. Tall, M. Bakar, International Journal of Mathematical Education in Science and Technology, 23, 1 39-50. (1992).

10. M. F. Özmantar, E. Bingölbali, H. Akkoç, Matematiksel kavram yanılgıları ve çözüm öneriler. (2010).

11. E. Güveli, Lise-1 fonksiyonlar konusunun web tabanlı ögretim tasarımı, uygulaması ve değerlendirilmesi. Doctoral dissertation. Karadeniz Teknik Üniversitesi, Fen Bilimleri Enstitüsü. (2004).

12. M. Carlson, M. Oehrtman, Key aspects of knowing and learning the concept of function. (2005).

13. A. Ural, Ege Eğitim Dergisi, 7, 2 75-94. (2006).

14. R. Dikici, T. İşleyen, Kastamonu Eğitim Dergisi, 11, 2 105-116. (2003).

15. H. Akkoç, Lise 3 öğrencilerinin çekirdek fonksiyon kavramını anlamaları. VI. Ulusal Fen Bilimleri ve Matematik Ĕ̆itimi Kongresi. (2004).

16. H. Tüzün, S. Arkün, E. Bayırtepe, F. Kurt, B. Yermeydan Uğur, Fonksiyonlar Konusunun Oyun Ortamında Öğretilmesi. 5. Matematik Sempozyumu. (2006).

17. T. Kutluca, A. Baki, Hacettepe Üniversitesi Eğitim Fakültesi Dergisi, 28, 3 319-331. (2013).

18. J. Brown, Proceedings of the 30th annual conference of the mathematics research group of Australasia (MERGA), 153 - 162. (2007).

19. J. B. Lagrange, International Journal for Technology in Mathematics Education, 21, 1. 3-10. (2014).

20. R. W. Mwangi, R. Waweru, C. W. Mwathi, Journal of Theoretical and Applied Information Technology, 26, 1 394-404. (2011). 